International Journal of Agricultural and Applied Sciences, June 2021, 2(1):41-49

https://www.agetds.com/ijaas

ISSN: 2582-8053

https://doi.org/10.52804/ijaas2021.214

Research Article

OPEN ACCESS

\title{
Molecular Characterization of chickpea genotypes and Identification of true hybrids by molecular markers
}

\author{
Bhavana Surduse $^{1}$, P. A. Mohanapure ${ }^{1}$, V.C. Khelurkar $^{1}$, M. P. Moharil ${ }^{1 *}$ A.A. Sapkal ${ }^{1}$, P. V. \\ Jadhav $^{1}$, D.R. Rathod ${ }^{1}$, S.B. Sakhare ${ }^{1}$, A. W. Thorat ${ }^{2}$ and R.B. Ghorade ${ }^{2}$ \\ ${ }^{I}$ Department of Agricultural Biotechnology, Dr. Panjabrao Deshmukh Krishi Vidyapeeth, Akola, India \\ ${ }^{2}$ Department of Agricultural Botany, Dr. Panjabrao Deshmukh Krishi Vidyapeeth, Akola, India \\ Corresponding author e-mail: mpmoharil@gmail.com
}

(Received: 03/02/2021; Revised: 25/05/2021; Accepted: 27/06/2021)

\begin{abstract}
Chickpea (Cicer arietinum L.) is the third most important grain legume cultivated in the arid and semi-arid regions of the world. In the present study Six crossing combinations were executed in chickpea comprising Chanoli and PKV Kabuli 4 as female parents and Virat, BDNGK-798 and WR- 315 as resistant male parents. Total 54 markers including 13 SCoT, 31 SSR, 5 STMS, 3 RAPD, 1 SCAR, and 1 ISSR, used for parental polymorphism and polymorphic markers UBC-855, $66 \%$ for TA-59 and $100 \%$ for TA-110, TA-135 and GA-16 were further used to hybridity assessments of F1 plants. The PIC value for polymorphic markers ranged from 0.15 to 0.89 with an average value of 0.46 . The highest PIC value was observed in UBC-855 marker (0.89), followed by TA-135 (0.62), TA-59 (0.50), and GA-16 (0.16) and lowest PIC value observed in TA-110 (0.15). From total crosses $31 \mathrm{~F} 1$ plants of six crosses were screened for true F1 hybridity assessment. STMS marker TA-59 was used for F1 hybrid purity assessment. This marker screened 31 F1 plants. TA-59 shows specific size amplicon in female and male parents. The results of this investigation proved that SSR markers are well polymorphic and more useful markers within species of chickpea genotypes to perform the molecular characterization and to test the genetic hybridity of F1 plants. Among the tested SSR markers TA-59, TA110, TA-135, GA-16, UBC-855 shows high percentage of polymorphism and PIC value which will were more helpful for parental diversity analysis and hybridity assessment.
\end{abstract}

Keywords: Chickpea, genotypes and identification.

\section{INTRODUCTION}

Chickpea (Cicer arietinum L.) is an ancient and third most important food legume crop after bean and pea, grown over 45 countries across five continents (Joshi et al. 2001). It is self-pollinating, annual, autogamous legume with chromosome number $(2 n=2 x=16)$ (Tekeoglu et al.2000). The estimated genome size of chickpea is $\sim 740 \mathrm{Mb}$ (Arumuganathan and Earle,1991). The 'desi' type chickpea is hardy in nature, gives better yield in Vidarbha region, Kabuli chickpea having soft seed coat and seems to have evolved from the desi types (Moreno and Cubero 1978). Chickpea plays a crucial role for supplying protein source; hence it is also called as the 'poor man's meat (Barman, 2012).

Chickpea protein rich in lysine and arginine but most deficient in sulphur containing amino acids viz. methionine and cystine. In general, kabuli type is rich in protein content than desi types. It is richer in calcium and phosphorus content than most other pulse crop (Singh et al. 2009).
Various abiotic and biotic stresses are the major bottleneck for increasing chickpea productivity. Biotic stress includes fungal, viral diseases, insects, nematodes, and parasitic weeds. Two fungal diseases, Ascochyta blight, caused by Ascochyta rabiei and Fusarium wilt, caused by Fusarium oxysporum f. sp. Ciceris (Nene and Reddy, 1987), are major constraints for chickpea production. Fusarium wilt is wide- spread in the chickpea growing areas of the world and has been reported from at least 33 countries (Dubey et al. 2007). The annual yield losses due to wilt have been estimated at 10- 90 per cent (Jimenez-Diaz et al. 1989).

Eight distinct physiological races of Fusarium oxysporum have been identified $(0,1 \mathrm{~A}, 1 \mathrm{~B} / \mathrm{C}, 2,3,4,5$ and 6), of which 1A, 2, 3 and 4 are prevalent in India (Haware and Nene, 1982) and the remaining races $(0,5$ and 6) reported from Spain (Jimenez - Diaz et al. 1989). Race 0 and $1 \mathrm{~B} / \mathrm{C}$ causes yellowing syndrome, whereas $1 \mathrm{~A}, 2,3,4,5$ and 6 lead to wilting syndrome. The disease is seed and soil borne. Symptoms of the disease can develop at any stage of plant growth, (Jiménez-Díaz et 
al.1989). However, symptoms are usually more visible in the early stages of flowering, 6 to 8 weeks after sowing and can also appear up to pod stage ("late wilt").

In the recent years, molecular markers have offered an opportunity to identify the purity of F1 plants as they are found to be highly polymorphic, independent of environmental interaction and represent the genomic constitution of a plant. The use of markers is well known and is in routine now a-days in selection of desirable plants in several self- and cross-pollinated crop species. Genetic purity of parental lines and hybrids is of crucial importance, as one percent reduction in purity of hybrid seed, results in a reduction of about $100 \mathrm{~kg} / \mathrm{ha}$ in yield of commercial crop. Traditionally genetic purity is done by Grow-out Tests (GOT), based on morphological assay. This method requires space for growing the samples drawn, considerable time till flowering/maturity (one season) and labour for raising the crop. Low levels of polymorphism of sufficient numbers of molecular markers such as microsatellite or simple sequence repeats (SSRs) are the main constraints in chickpea breeding program. Hence, identification of polymorphic markers with respective to selected genotypes is the challenging and used of polymorphic markers in the hybridity assessment is important to hasten the breeding program of chickpea crop.

The objectives of the present study were to perform the parental polymorphism in the selected genotypes and identification of true crosses through polymorphic markers (SSR, ISSR, RAPD, SCAR and STMS) which will be further utilized for hybridity assessment and molecular breeding program to hasten the process of variety development.

\section{MATERIALS AND METHODS}

The present investigation was carried out during 20182020 at Biotechnology Centre, Department of Agricultural Botany, Dr. Panjabrao Deshmukh Krishi Vidyapeeth, Akola. The details of the experiments conducted, and materials used are presented below. All molecular experiments conducted at Biotechnology Centre, Department of Agricultural Botany, Dr. PDKV, Akola. Field experiments related to breeding were carried out at Pulses Research Unit, Dr. PDKV, Akola. Chickpea genotypes
Female line PKV Kabuli-4 and Chanoli (Dr. PDKV. Akola) and male Virat (MPKV Rahuri) BDNGK-798 (VNMKV, Parbhani) and WR-315 (ICRISAT) lines were kindly provided by Pulses Research Unit, Akola.

During present investigation six crosses combinations were executed in chickpea comprising PKV Kabuli 4 and Chanoli as susceptible female parents and BDNGK-798, Virat, and WR-315 as resistant male parent.

In Chanoli crosses were executed Chanoli X Virat, Chanoli X BDNGK-798 and Chanoli X WR-315. Similarly, for PKV Kabuli 4 were PKV Kabuli 4 X Virat, PKV Kabuli 4 X BDNGK-798 and PKV Kabuli 4 X WR-315.

\section{DNA isolation}

Good quality of DNA was isolated from the young leaves of parent and $F_{1}$ plants by following Cetyl Trimethyl Ammonium Bromide (CTAB) method described by Doyle and Doyle, 1987. Quantity and quality of DNA samples were assessed by Nano photometer by measuring O.D. at 260/280 nm. The quality of genomic DNA was confirmed on $0.8 \%$ agarose gel. Total 54 markers were used for parental polymorphism survey. The details of primers and their sequence along with melting temperature are mentioned in Table 1.

\section{PCR amplification and Polyacrylamide Gel \\ Electrophoresis}

Parental polymorphism was carried out using 54 molecular markers. PCR amplification was performed in $20 \mu \mathrm{l}$ reaction containing $10 \mathrm{X}$ PCR buffer $17.5 \mathrm{mM}$ $\mathrm{MgCl}_{2}$, $50 \mathrm{ng} / \mu \mathrm{l}$ sample DNA, 10 pmol primers, 10

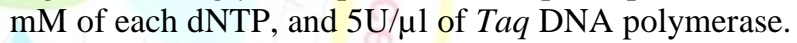
The temperature profile varied as per primers, for SCoT/SSR/ STMS/ ISSR primers an initial denaturation at $94{ }^{\circ} \mathrm{C}$ for $3 \mathrm{~min}$, followed by 35 cycles of denaturation at $94{ }^{\circ} \mathrm{C}$ for $30 \mathrm{sec}$, annealing was checked by using gradient PCR for every primer at $55-62{ }^{\circ} \mathrm{C}$ for $45 \mathrm{sec}$, extension at $72{ }^{\circ} \mathrm{C}$ for $1 \mathrm{~min}$ and final extension at $72{ }^{\circ} \mathrm{C}$ for $10 \mathrm{~min}$ was followed by hold at $4^{\circ} \mathrm{C}$. The separations of PCR products were resolved on $10 \%$ PAGE.

Total 54 markers including 13 SCoT, 31 SSR, 5 STMS, 3 RAPD, 1 SCAR, and 1 ISSR, used for parental polymorphism and only polymorphic markers were further used to hybridity assessments of $F_{1}$ plants.

The observed banding pattern studied for parental survey is shown in Plate 1.

Table 1. List of the molecular marker used in the present investigation

\begin{tabular}{|l|l|l|l|l|}
\hline \multirow{2}{*}{ S.No. } & \multirow{2}{*}{ Primers } & Position & Nucleotide sequence & $\begin{array}{l}\text { Annealing } \\
\text { temperature }\end{array}$ \\
\hline \multirow{2}{*}{1} & \multirow{2}{*}{ TA-1 } & $\mathrm{F}$ & TGAAATATGGAATGATTACTGAGTGAC & 58.9 \\
\cline { 3 - 5 } & & $\mathrm{R}$ & TATTGAAATAGGTCAGGCTTATAAAAA & 55.9 \\
\hline \multirow{2}{*}{2} & \multirow{2}{*}{ TA-2 } & $\mathrm{F}$ & AAATGGAAGAAGAATAAAAACGAAAC & 55.3 \\
\cline { 3 - 5 } & \multirow{2}{*}{3} & $\mathrm{R}$ & TTCCATTCTTTATTATCCATATCACTACA & 58.2 \\
\hline \multirow{2}{*}{4} & TA-3 & $\mathrm{F}$ & AATCTCAAAATTCCCCAAAT & 50.1 \\
\cline { 3 - 5 } & \multirow{2}{*}{ TA-14 } & $\mathrm{R}$ & ATCGAGGAGAGA AGA ACCAT & 55.3 \\
\cline { 3 - 5 } & & $\mathrm{R}$ & TGACTTGCTATTTAGGGAACA & 54.0 \\
\hline
\end{tabular}




\begin{tabular}{|c|c|c|c|c|}
\hline \multirow{2}{*}{5} & \multirow{2}{*}{ TA-18 } & $\mathrm{F}$ & AAAATAATCTCCACTTCACAAATTTTC & 55.9 \\
\hline & & $\mathrm{R}$ & ATAAGTGCGTTATTAGTTTGGTCTTGT & 58.9 \\
\hline \multirow{2}{*}{6} & \multirow{2}{*}{ TA-27 } & $\mathrm{F}$ & ACAATTCCACTTAATCTTTGC & 52.0 \\
\hline & & $\mathrm{R}$ & AATTTAGCCTACAGACACACACA & 57.1 \\
\hline \multirow{2}{*}{7} & \multirow{2}{*}{ TA-28 } & $\mathrm{F}$ & TAATTGATCATACTCTCACTATCTGCC & 60.4 \\
\hline & & $\mathrm{R}$ & TGGGAATGAATATATTTTTGAAGTAAA & 54.3 \\
\hline \multirow{2}{*}{8} & \multirow{2}{*}{ TA-37 } & $\mathrm{F}$ & ACTTACATGAATTATCTTTCTTGGTCC & 58.9 \\
\hline & & $\mathrm{R}$ & CGTATTCAAATAATCTTTCATCAGTCA & 57.4 \\
\hline \multirow{2}{*}{9} & \multirow{2}{*}{ TA-59 } & $\mathrm{F}$ & ATCTAAAGAGAAATCAAAATTGTCGAA & 55.9 \\
\hline & & $\mathrm{R}$ & GCAAATGTGAAGCATGTATAGATAAAG & 58.9 \\
\hline \multirow{2}{*}{10} & \multirow{2}{*}{ TA-64 } & $\mathrm{F}$ & ATATATCGTAACTCATTAATCATCCGC & 58.9 \\
\hline & & $\mathrm{R}$ & AAATTGTTGTCATCAAATGGA AAATA & 53.8 \\
\hline \multirow{2}{*}{11} & \multirow{2}{*}{ TA-71 } & $\mathrm{F}$ & CGATTTAACACAAAACACAAA & 50.1 \\
\hline & & $\mathrm{R}$ & CCTATCCATTGTCATCTCGT & 55.3 \\
\hline \multirow{2}{*}{12} & \multirow{2}{*}{ TA-96 } & $\mathrm{F}$ & TGTTTTGGAGAAGAGTGATTC & 54.0 \\
\hline & & $\mathrm{R}$ & TGTGCATGCAAATTCTTACT & 51.2 \\
\hline \multirow{2}{*}{13} & \multirow{2}{*}{ TA-110 } & $\mathrm{F}$ & ACACTATAGGTATAGGCATTTAGGCAA & 60.4 \\
\hline & & $\mathrm{R}$ & \begin{tabular}{|l} 
TTCTTTATAAATATCAGACCGGAAAGA \\
\end{tabular} & 57.4 \\
\hline \multirow{2}{*}{14} & & $\mathrm{~F}$ & TCTTTCTTTGCTTCCAATGT & 51.2 \\
\hline & $1 A-150$ & $\mathrm{R}$ & GTAAATCCCACGAGAAATCAA & 54.0 \\
\hline 15 & $\mathrm{TA} 125$ & $\mathrm{~F}$ & TGGTTGGAAATTGATGTTTT & 49.1 \\
\hline 15 & | & $\mathrm{R}$ & GTGGTGTGAGCATAATTCAA & 53.2 \\
\hline 16 & TA 180 & $\mathrm{~F} O$ & CATCGTGA ATATTGA AGGGT & 53.2 \\
\hline 10 & $1 A-180$ & $\mathrm{R}$ & CGGTAAATAAGTTTCCCTCC & 55.3 \\
\hline 17 & Tत 104 & $\mathrm{~F}$ & TTTTTGGCTTATTAGACTGACTT & 53.5 \\
\hline 11 & $1 \mathrm{~A}-194$ & $\mathrm{R}$ & TTGCCATAAAATACAAAATCC & 50.1 \\
\hline 18 & T Т 200 & $\mathrm{~F}$ & TTTCTCCTCTACTATTATGATCACCAG & 60.4 \\
\hline 10 & $1 \mathrm{~A}-200$ & $\mathrm{R}$ & TTGAGAGGGTTAGAACTCATTATGTTT & 58.2 \\
\hline & & $\mathrm{F}$ & TCATGCTTGTTGGTTAGCTAGAAA & 57.6 \\
\hline 19 & TAA-60 & $\mathrm{R}$ & CAAAGACATAATCGAGTTAAAGAAAA & 55.3 \\
\hline 20 & TR_1 & $\mathrm{F}$ & CGTATGATTTTGCCGTCTAT & 53.2 \\
\hline 20 & $1 \mathrm{~K}-1$ & $\mathrm{R}$ & ACCTCAAGTTCTCCGAAGT & 54.5 \\
\hline 21 & TP 10 & $\mathrm{~F}$ & TCAGTATCACGTGTAATTCGT & 54.0 \\
\hline 21 & $\mid 1 K-19$ & $\mathrm{R}$ & CATGAACATCAAGTTCTCCA & 53.2 \\
\hline 22 & TS 15 & $\mathrm{~F}$ & TGACACAAAATTGTCTCTTGT & 52.0 \\
\hline 22 & $10-4$ & $\mathrm{R}$ & TGTTCTTAACGTAACTAACCTAA & 53.5 \\
\hline 23 & TTS 8? & $\mathrm{F}$ & TCAAGATTGATATTGATTAGATAAAAGC & 56.3 \\
\hline 20 & $\mid 13-02$ & $\mathrm{R}$ & \begin{tabular}{|l} 
CTTTATTTACAACTTGCACAACACTAA \\
\end{tabular} & 57.4 \\
\hline 24 & STMS $?$ & $\mathrm{~F}$ & ATTTTACTTTACTACTTTTTTCCTTTC & 54.3 \\
\hline 24 & $51 \mathrm{IIN}-2$ & $\mathrm{R}$ & AATAAATGGA GTGTAAATTTCATGTA & 53.8 \\
\hline & & $\mathrm{F}$ & GTATCTACTTGTAATATTCTCTTCTCT & 57.4 \\
\hline 25 & STMS-11 & $\mathrm{R}$ & ATATCATAAACCCCCCAC & 51.4 \\
\hline 26 & STMS 13 & $\mathrm{~F}$ & TATGTTAAAAGAGAAAGAAGAAGTGAT & 55.9 \\
\hline 20 & SIIVIS-15 & $\mathrm{R}$ & TTTTATTAGTTGTCGAAATGTATATCA & 54.3 \\
\hline 27 & STMS 20 & $\mathrm{~F}$ & CTTNTCGTCATCATCGTTTTG & 54.9 \\
\hline 21 & SIIVIS-20 & $\mathrm{R}$ & CACССТАСТTTТTTCСАCСАC & 57.9 \\
\hline 28 & STMS 24 & $\mathrm{~F}$ & AAAGA CAGGTTTTAATCCAAAA & 50.9 \\
\hline 20 & SIIVIS-24 & $\mathrm{R}$ & CTAATCTTTCTTCTTCTTTTGTCAT & 54.8 \\
\hline 20 & CS_27 & $\mathrm{F}$ & AGCTGGTCGCGGGTCAGAGGAAGA & 67.8 \\
\hline 29 & CD-2t & $\mathrm{R}$ & AGTGGTCGCGATGGGGCCATGG TG & 69.6 \\
\hline 30 & & $\mathrm{~F}$ & ACCTGGTCGCGGGTCAGAGGAAGA & 67.8 \\
\hline 30 & $\mathrm{CS}-2 / \mathrm{A}$ & $\mathrm{R}$ & AGTGGTCGCGATGGGGCCATGGTG & 69.6 \\
\hline 31 & $G A-4$ & $\mathrm{~F}$ & TTGCGTGTCAATCTCATTGG & 55.3 \\
\hline 31 & $\mathrm{OA}^{-4}$ & $\mathrm{R}$ & TCAACACCCCTAACTCGGA C & 59.4 \\
\hline 32 & GA11 & $\mathrm{F}$ & GTTGA GCAACAAAGCCACAA & 55.3 \\
\hline & & $\mathrm{R}$ & TTCTTGTCTGGTTGTGTGA GC & 57.9 \\
\hline
\end{tabular}




\begin{tabular}{|c|c|c|c|c|}
\hline \multirow{2}{*}{33} & \multirow{2}{*}{ GA-16 } & $\mathrm{F}$ & CACCTCGTACCATGGTTTCTG & 59.8 \\
\hline & & $\mathrm{R}$ & TAAATTTCATCCTCTCCGGC & 55.3 \\
\hline \multirow{2}{*}{34} & \multirow{2}{*}{ GAA-40 } & $\mathrm{F}$ & TTGACGCAGAGAACTCTCAA & 55.3 \\
\hline & & $\mathrm{R}$ & ATTGGTGTGATGGGTGGATT & 55.3 \\
\hline \multirow{2}{*}{35} & \multirow{2}{*}{ GAA-42 } & $\mathrm{F}$ & CGCTTCAGTGTAGATATTATTCAAACA & 58.9 \\
\hline & & $\mathrm{R}$ & ТСТСТСТTТСТСТTCAACACGC & 58.4 \\
\hline \multirow{2}{*}{36} & \multirow{2}{*}{ GAA-44 } & $\mathrm{F}$ & AGCAAGCCCATGA TTTTCTC & 55.3 \\
\hline & & $\mathrm{R}$ & ATGA CATTCCAATCGGCTTC & 55.3 \\
\hline \multirow{2}{*}{37} & \multirow{2}{*}{ GAA-45 } & $\mathrm{F}$ & TTGGGA TCCATTTCATCCAT & 53.2 \\
\hline & & $\mathrm{R}$ & GCCTGGA AGTCACACACTTG & 59.4 \\
\hline \multirow{2}{*}{38} & \multirow{2}{*}{ GAA-46 } & $\mathrm{F}$ & TCTCCTGTGA ATGA ACCGA A & 55.3 \\
\hline & & $\mathrm{R}$ & CTGA GCAACAAAATCAGCCA & 55.3 \\
\hline 39 & UBC-170 & Seq. & ATCTCTCCTG & 24.8 \\
\hline 40 & UBC-855 & Seq. & ACACACACACACACACACYT & 56.3 \\
\hline 41 & OPC14-1 & Seq. & TGCGTGCTTG & 28.9 \\
\hline 42 & SCoT 11 & Seq. & AAGCAATGGCTACCACCA & 53.7 \\
\hline 43 & SCoT 12 & Seq. & ACGACATGGCGACCAACG & 58.2 \\
\hline 44 & SCoT 13 & Seq. & ACGACATGGCGACCATCG & 58.2 \\
\hline 45 & SCoT 14 & Seq. & ACGACATGGCGACCACGC & 60.5 \\
\hline 46 & SCoT 17 & Seq. & ACCATGGCTACCACCGAG & 58.2 \\
\hline 47 & SCoT 18 & Seq. & ACCATGGCTACCACCGCC & 60.5 \\
\hline 48 & SCoT 19 & Seq. & ACCATGGCTACCACCGGC & 60.5 \\
\hline 49 & SCoT 20 & Seq. & ACCATGGCTACCACCGCG & 60.5 \\
\hline 50 & SCoT 25 & Seq. & ACCATGGCTACCACCGGG & 60.5 \\
\hline 51 & SCoT 27 & Seq. & ACCATGGCTACCACCGTG & 58.2 \\
\hline 52 & SCoT 28 & Seq. & CCATGGCTACCACCGCCA & 60.5 \\
\hline 53 & SCoT 33 & Seq. & CCATGGCTACCACCGCAG & 60.5 \\
\hline 54 & SCoT 34 & Seq. & ACCATGGCTACCACCGCA & 58.2 \\
\hline
\end{tabular}

Table 2. Details of the informative markers observed in present investigation

\begin{tabular}{|l|l|l|l|l|l|}
\hline Primers & $\begin{array}{l}\text { No. of } \\
\text { amplicons }\end{array}$ & $\begin{array}{l}\text { Monomorphic } \\
\text { bands }\end{array}$ & $\begin{array}{l}\text { Polymorphic } \\
\text { band }\end{array}$ & $\begin{array}{l}\text { Polymorphism } \\
\%\end{array}$ & $\begin{array}{l}\text { PIC } \\
\text { Value }\end{array}$ \\
\hline TA - 59 & 3 & 1 & 2 & 66 & 0.50 \\
\hline TA - 110 & 2 & - & 2 & 100 & 0.15 \\
\hline TA - 135 & 4 & - & 4 & 100 & 0.62 \\
\hline GA - 16 & 4 & - & 4 & 100 & 0.16 \\
\hline UBC- 855 & 10 & 6 & 4 & 40 & 0.89 \\
\hline Total & 23 & 6 & 16 & 406 & 2.32 \\
\hline Average & 4.6 & 1.4 & 3.2 & 81.2 & 0.46 \\
\hline
\end{tabular}

\section{RESULTS AND DISCUSSION}

\section{Parental polymorphic survey}

Variation between individual genotypes or between populations in a species, can be easily evaluated using a variety of molecular markers. Microsatellite marker is currently the most preferred molecular marker system owing to their highly desirable properties viz., abundance, hyper-variability, high reproducibility, and suitability for high throughput analysis also produces very high allelic variations even among very closely related varieties. Therefore, the 41 molecular markers were used in the parental polymorphic survey along with 13 SCoT markers.

Collard and Mackill (2009) describes that ATG start codons are incorporated into random primers to generate polymorphic fragments from the genome. Therefore, the 13 SCoT markers also used to study the start codon variation in the selected chickpea lines.

The polymorphic markers used in present study shows the discriminating banding pattern between parents. The details of the informative markers and their banding pattern is mentioned in the Table 2. and Plate 2. 
In polymorphic markers profiling, total alleles per locus were 4.6, whereas average number of monomorphic and polymorphic alleles were 1.4 and 3.2 , respectively. The polymorphic percentage of markers were $40 \%$ for UBC$855,66 \%$ for TA-59 and $100 \%$ for TA-110, TA-135 and GA-16, showed in Table 2. These finding also corelate with Solanki et al., 2010 who performed the parental polymorphic survey for five Lentil genotypes using sixty RAPD and 35 SSR markers and observed the twenty RAPD and 10 SSRs polymorphic markers which further used in the hybridity assessment of 24 F1 lentil individuals and confirmed the 5 true hybrids.

The PIC value for informative profiling ranged from 0.15 to 0.89 with an average value of 0.46 . The highest PIC value was observed in UBC-855 marker (0.89), followed by TA-59 (0.50), TA-135 (0.62) and GA-16 $(0.16)$ and lowest PIC value in TA-110 (0.15).

\section{Identification of true $\mathrm{F}_{\mathbf{1}}$ hybrids}

Molecular markers are efficient tool to identify and evaluate true $F_{1}$ hybrids. Therefore, the markers which are polymorphic were used for identification of true $F_{1}$ hybrids. The immense potentiality of molecular marker for the measuring the genetic purity as compare the morphological or biochemical rail has already been reported to several crop. PCR based marker has been employed successfully for parentage verification, hybrid identification and purity testing (Paran et al., 1995).

For analysing the genetic purity of hybrids, the banding patterns of polymorphic markers were compared and polymorphic markers between parents were identified. The size of a polymorphic marker was analysed on visual basis which was further used to test respective hybrids. The purity of the $F_{1} s$ was confirmed when they showed the presence of male and female both parent alleles.

From total crosses $31 \mathrm{~F}_{1}$ plants of six crosses were screened $F_{1}$ hybridity assessment. These plants were used to obtain $\mathrm{F}_{2}$ plants for developing the wilt mapping population. Apart from all markers one informative marker were utilized for testing $\mathrm{F}_{1}$ hybridity based on the parental polymorphism banding pattern.

\section{F 1 hybridity testing by STMS TA-59 marker}

STMS marker TA-59 was used for $F_{1}$ hybrid purity assessment. This marker screened $31 \mathrm{~F}_{1}$ plants. TA-59 shows specific size amplicon in female and male parents. It shows amplicon of size $258 \mathrm{bp}$ in resistant male parent Virat, WR-315 and 257bp and 256 bp amplicon in female parent PKV Kabuli 4 and Chanoli, respectively. STMS marker, (TA-59) screened on the $31 \mathrm{~F}_{1}$ plants of crosses, Chanoli X Virat, Chanoli X BDNGK-798, Chanoli X WR-315, PKV Kabuli 4 X Virat, PKV Kabuli 4 X WR-315, PKV Kabuli 4 X BDNGK-798 the banding pattern were shown in Plate 3.

Four $F_{1}$ plants of cross Chanoli x BDNGK-798 shows presence of both amplicon of parents Chanoli (257bp) and BDNGK-798 (258bp). Hence all four $\mathrm{F}_{1} \mathrm{~s}$ were confirmed to be true hybrid. Similarly, one $\mathrm{F}_{1}$ plants derived from Chanoli X WR-315 and two Chanoli X Virat confirmed to be true hybrid. Solanki et al.,2010 performed the hybridity assessments for $24 \mathrm{~F} 1$ plants and proves the importance of RAPD and ISSR markers in confirmation of true $\mathrm{F} 1$ individuals.

In crossed derived from PKV (Kabuli $4 \mathrm{x}$ Virat) out of five $F_{1}$ plants two shows presence of both amplicon of parents PKV Kabuli 4 (256bp) and Virat (258bp). These two $\mathrm{F}_{1} \mathrm{~s}$ were confirmed to be true hybrids. Similarly, three from $F_{1}$ plants of crossed PKV Kabuli $4 \mathrm{x}$ BDNGK-798 and one from cross of PKV Kabuli $4 \mathrm{X}$ WR-315 were confirmed as true hybrid as shown in Plate 3.

The primer TA-59 was mapped on linkage group 2 on which genes for disease resistance were present (Winter et al., 2000). This marker gives the specific banding amplicon in male and female parent which is helpful to discriminate the true F1s hybrids.

Thus, determine hybrid purity important to develop a mapping population for reviewing the genetics or mapping of gene controlling desirable traits. The genetic improvement for wilt resistance can be made in lentil if genetics of this trait is known. This can only be studied if a correct segregating population is available. For obtaining a true segregating population, it is must that crossed seeds are to be true $\mathrm{F}_{1} \mathrm{~s}$ (Solanki et al.,2010.) In chickpea, selfing is commonly occurred. Therefore, identification of true $\mathrm{F}_{1}$ plants using molecular markers in present study will positively reduce chance of the further errors. Moreover, it will save time, efforts and money required to switch an incorrect segregating population.

\section{CONCLUSION}

The results of present work proved that SSR markers are well polymorphic and more useful to perform the molecular characterization and to test the genetic hybridity of $F_{1}$ plants. The polymorphic markers can be helpful for diversity analysis and speedup the breeding program.

Thus, determining hybrid purity is important to develop true mapping population for studying the nature of genetics associated with trait of interest. Because use of segregating F2 population having mixture of selfed and true F1 plants hampers the results of genetic mapping and purity of population. In chickpea selfing and mixture are commonly occurred. Therefore, identification true F1 plants using markers in the present study will certainly reduced the efforts and time of breeding program. Moreover, it will helpful to speedup the breeding technique as compare to traditional one which helpful to farmers community.

\section{ACKNOWLEDGEMENTS}

Authors are grateful to Pulses Research Unit Dr. PDKV., Akola and ICRISAT (Hyderabad) for providing experimental materials for the field experiment. The authors also acknowledge the Biotechnology Centre, Dr. PDKV, Akola for providing their working facility and cooperation. 


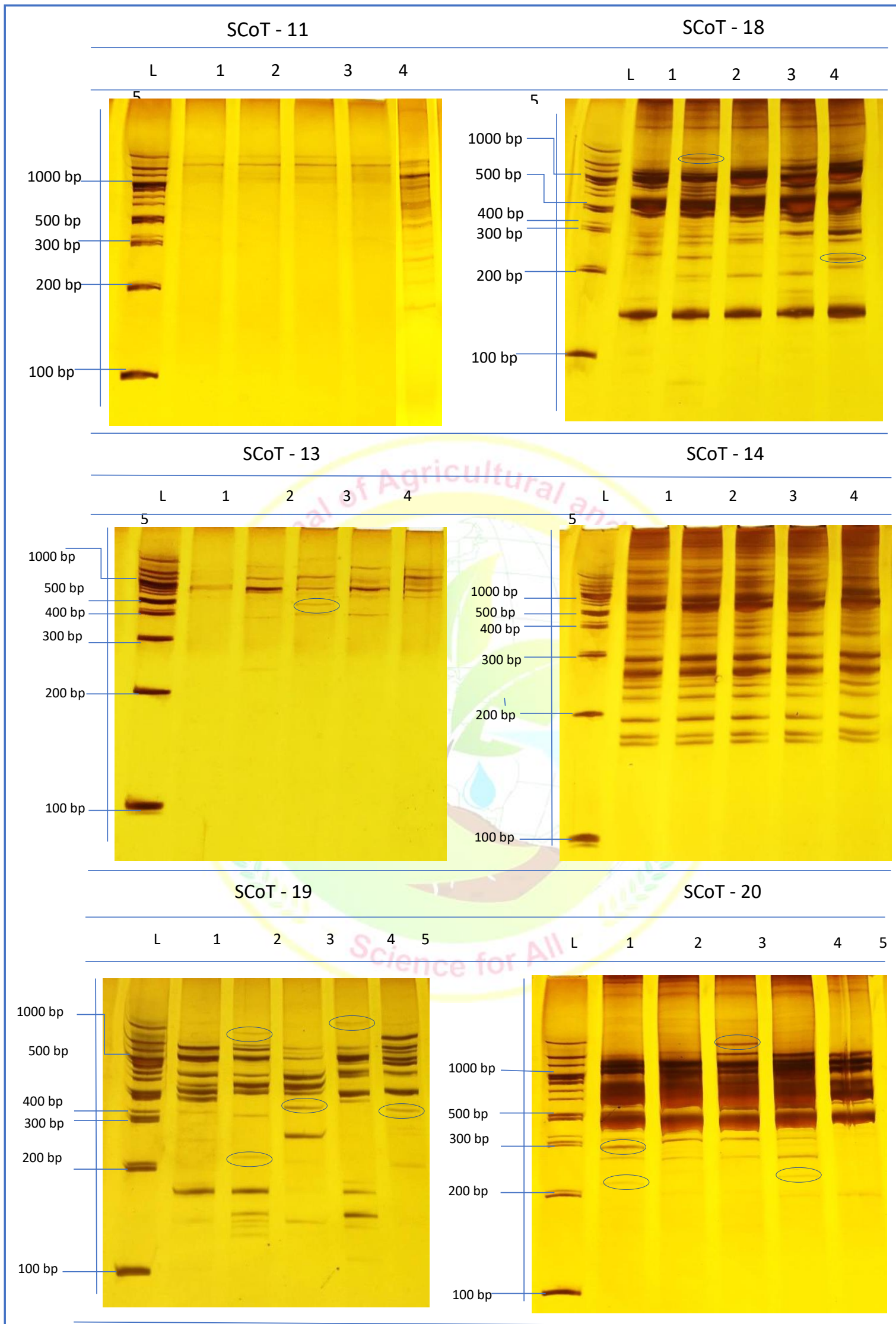

Plate 1. Start codon targeted (SCoT) marker profiling in Chickpea genotypes Lane L- 100 bp, 1- Chanoli, 2- Kabuli-4, 3- Virat, 4- BDNGK 798, 5- WR 315 


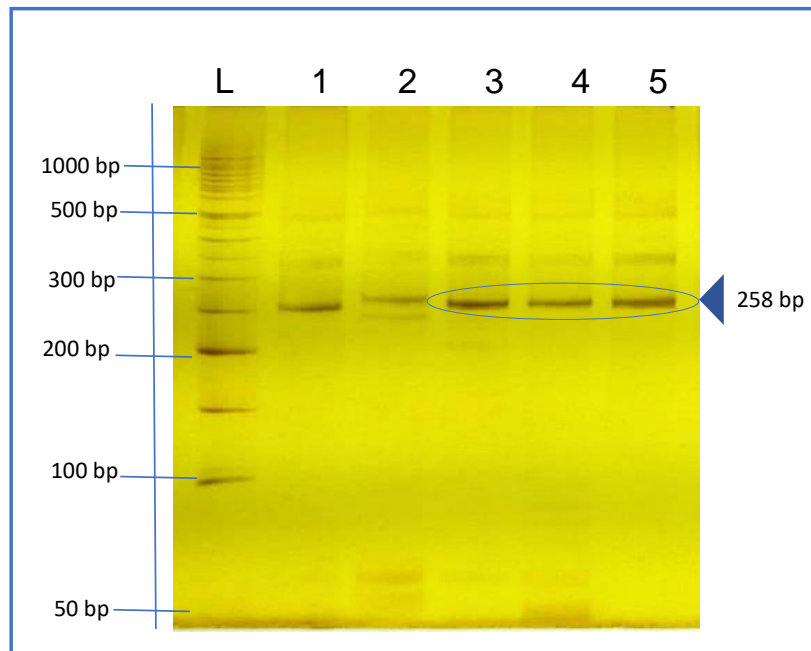

TA-59

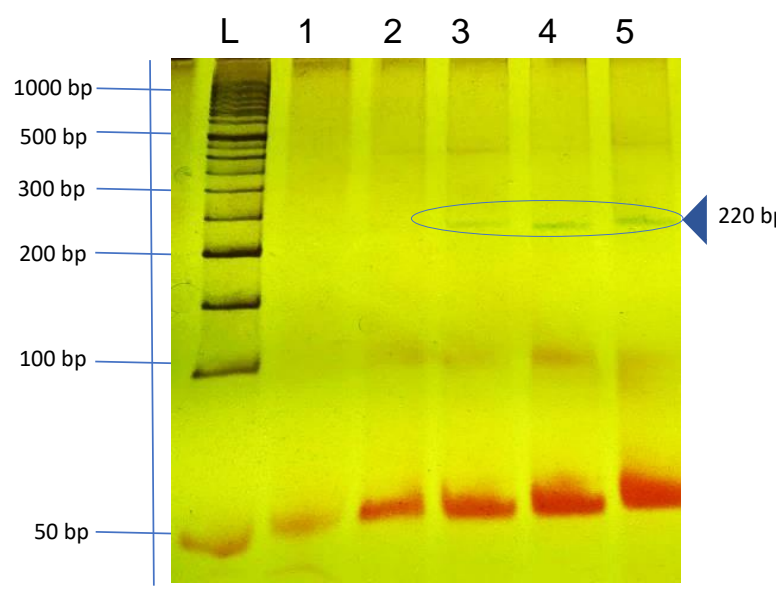

TA-110

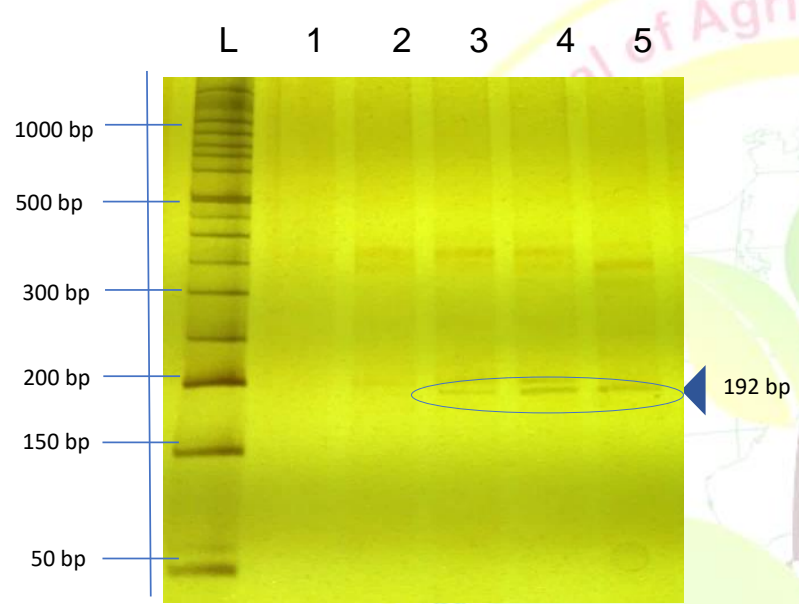

TA-135
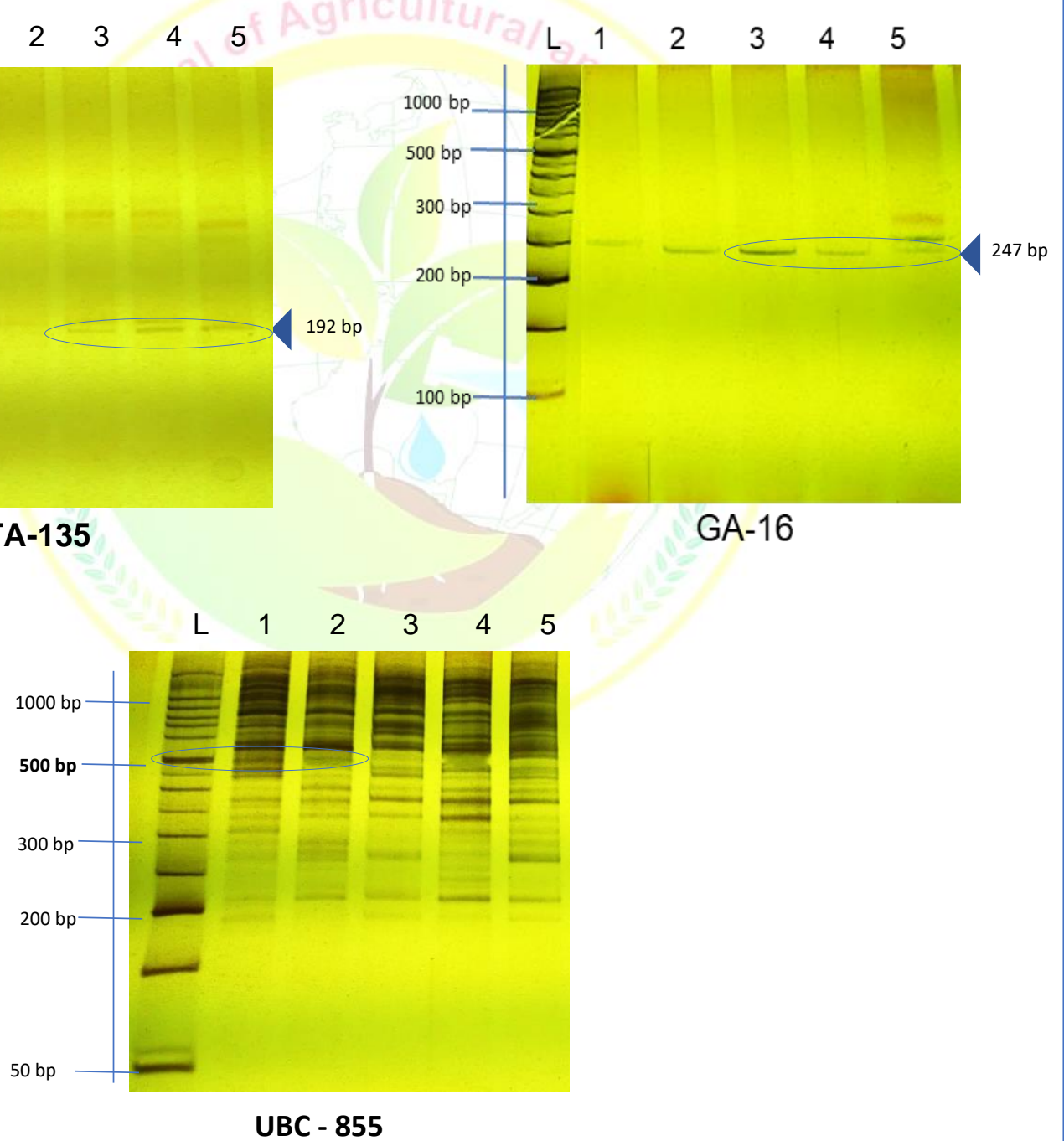

Plate 2. Parental polymorphism in Chickpea genotypes by informative markers Lane L- 50 bp, 1- Chanoli, 2- Kabuli-4, 3- Virat, 4- BDNGK 798, 5- WR 315 


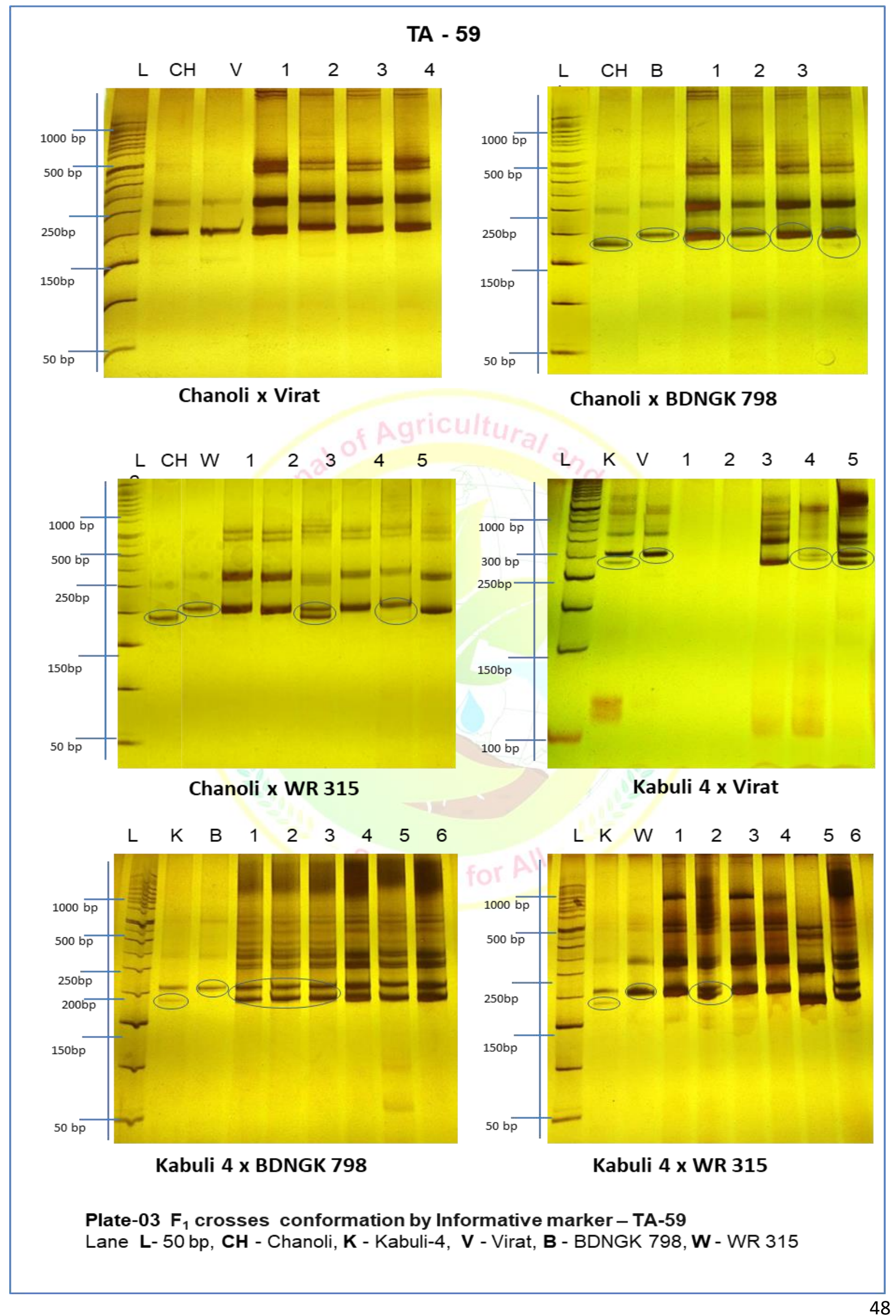




\section{REFERENCES}

Allahverdipoor, K. H; B. Bahramnejad and J. Amini, 2011. Selection of molecular markers associated with resistance to Fusarium wilt disease in chickpea (L.) using multivariate statistical techniques. Australian Journal of Plant Science. 5(13):1801-1809.

Arumuganathan, K. and E. D. Earle, 1991. Nuclear DNA content of some important plant species. Plant Molecular Biology Reporter. 9:208-218.

Barman, P. 2012. Study on association of molecular markers with Fusarium wilt resistance in chickpea (Cicer arietinum L.). Thesis submitted to Gauhati University.

Choudhary, C.K. and D. Abhishek, 2010. Interspecific detection of polymorphism using sequence tagged microsatellites (STMS) in chickpea. Electronic Journal of Plant Breeding. 1(4): 484-488.

Collard, B. C. Y. and D. J. Mackill, 2009. Start CodonTargeted (SCoT) Polymorphism: A Simple, Novel DNA Marker Technique for Generating Gene-Targeted Markers in Plants. Plant MolBiol Rep. 27:86-93.

Doyle, J. J. and J. L. Doyle, 1987. A rapid DNA isolation procedure for small amounts of fresh leaf tissue. Phytochem. Bull. 19: 11-15.

Dubey, S. C.; M. Suresh and B. Singh, 2007. Evaluation of Trichoderma species against Fusariumoxysporumf. sp. ciceris for integrated management of chickpea wilt. Biol. Control. 40:118-127.

Haware, M. P. and Y. L. Nene, 1982. Races of Fusariumoxysporumf.sp.Ciceri.Pl. Dis., 66: 809810.

Haware, M. P; Y. L. Nene and M. Natarajan, 1996. The survival of Fusariumoxysporum f. sp. ciceri in the soil in the absence of chickpea. Phytopathol. Mediterr. 35:9-12.

Jimenez-Diaz, R. M; A. Trapero-Crass, L. A. Carbera De and J. Coina, 1989. Races of Fusariumoxysporumf.sp.Ciceri infecting chickpeas in Southern Spain. In: Vascular wilt diseases of plants. Eds. Tjamos, E.C. and Beckman, C.H., pp 515-520.
Joshi, P. K; P. Parthasarathy Rao, C. L.L. Gowda, R. B. Jones, S.N. Silim, K. B. Saxena and J. Kumar, 2001. The world chickpea and pigeonpea economies: Facts, trends, and outlook. Patancheru 502 324, Andhra Pradesh, India. International Crops Research Institute for the Semi-Arid Tropics. pp-62.

Moreno, M. T. and J. I. Cubero, 1978. Variation in Cicer aritenium L. Euphytica. 27: 465- 485.

Nene, Y.L. and M. V. Reddy, 1987. Chickpea diseases and their control. In: The chickpea. Eds. Saxena, M.C. and Singh, K.B. pp 233-70. CAB International/ Oxon, U.K.

Paran, I., Horowitz, M., Zamir, D., Wolf, S., 1995. Random amplified polymorphic DNA markers are useful for purity determination of tomato hybrids. HortScience 30, p. 377.

Singh, C; P. Singh and R. Singh, 2009. Modern Techniques of Raising Field Crops. 195.

Solanki R.M. Sweta Singh, J. Kumar Molecular marker assisted testing of hybridity of F1 plants in lentil Journal of Food Legumes 23(1): 21-24, 2010.

Tekeoglu, M; D. K. Santra, W. J. Kaiser and F. J. Muehlbauer, 2000. Ascochyta blight resistance inheritance in three chickpea recombinant inbred line populations. Crop Science.40:1251-1256.

Winter, P. T; S. M. Pfaff, B. Udupa, P. C. Huttel, S. Sharma, R. Sahi, R. Arreguin-Espinoza, F Weigand, F. J. Muehlbauer and G. Kahl, 1999. Characterization and mapping of sequence-tagged microsatellite sites in the chickpea (Cicer arietinum L.) genome. Mol. Gen. Genet. 262: 90101.

Winter, P; A. M. Benko-Iseppon and B. Huttel, 2000. A linkage map of chickpea (CicerarietinumL.) genome based on recombinant inbred lines from a $C$. arietinum $\mathrm{x}$ C. reticulatumcross: localization of resistance genes for Fusarium wilt races 4 and 5. Theor Appl Genet. 101:1155-1163.

Citation: Surduse, B.; Mohanapure, P. A.; Khelurkar, V.C.; Moharil, M. P.; Sapkal, A.A., Jadhav, P. V.; Rathod, D.R.; Sakhare, S.B.; Thorat, A. W. and Ghorade, R.B. 2021. Molecular Characterization of chickpea genotypes and Identification of true hybrids by molecular markers. International Journal of Agricultural and Applied Sciences, 2(1):41-49. https://doi.org/10.52804/ijaas2021.214

Copyright: (C) Surduse, B. et. al. 2021. Creative Commons Attribution 4.0 International License. IJAAS allows unrestricted use, reproduction, and distribution of this article in any medium by providing adequate credit to the author(s) and the source of publication. 